\title{
Effects of forward \& backward walking training with progressive body weight supported on stroke patients' ambulatory ability
}

\author{
Kyung-Hoon Kim ${ }^{a}$, Suk-Min Lee ${ }^{b}$ \\ ${ }^{a}$ Department of Physical Therapy, Bundang Jesaeng General Hospital, Seongnam, Republic of Korea \\ ${ }^{\mathrm{b}}$ Department of Physical Therapy, College of Health and Welfare, Sahmyook University, Seoul, Republic of Korea
}

Objective: In the present study, the effects of progressive body weight support treadmill forward \& backward walking training (FBWT), progressive body weight support treadmill forward walking training (FWT), and progressive body weight support treadmill backward walking training (BWT), and on stroke patients' ambulatory abilities were examined.

Design: Randomized controlled trial.

Methods: A total of 36 chronic stroke patients were divided into three groups with 12 subjects in each group. Each of the groups performed one of the progressive body weight supported treadmill training methods for 30 minute, six times per week for three weeks, and then received general physical therapy without any other intervention until the follow-up tests. For the assessment of the step length, total double support, cadence, gait were measured using optogait and the 10-m walk test (10MWT), 6 minutes walk test (6MWT).

Results: In the within group comparisons, all the three groups showed significant differences between before and after the intervention $(p<0.05)$. In the comparison of the three groups, there were significant differences among the three groups in stride length, double limb support stance, cadence, 10MWT, and 6MWT in the third week, and only in stride length, 10MWT, and 6MWT test in the sixth week $(p<0.05)$.

Conclusions: This study verified that progressive body weight-supported treadmill gait training positively affected the gait ability of stroke patients in an actual gait environment. It also showed that FBWT group was more effective than FWT group and BWT group training.

Key Words: Backward gait training, Forward gait training, Gait, Progressive body weight-supported, Stroke

\section{Introduction}

The gait patterns of stroke patients are characterized by slow gait cycle and speed, differences in stride length between the step length of the paretic side and that of the non-paretic side, and a short stance phase and relatively long swing phase on the paretic side [1,2]. Recovery of gait ability is directly related to securing independence and returning functions to before-damage levels. Therefore, the most important purpose of rehabilitation should be considered improvement of gait function [3].

In order to improve the problem of gait in stroke patients, different methods have been tried clinically, including gait training using parallel bars or on the ground, in addition to existing treatment methods. One novel method, body weight-supported treadmill training, has been utilized as a new therapeutic approach [4-6].

Treadmill training (with or without body-weight support) has emerged as an intervention that improves walking speed in people who have had a stroke [7,8]. In addition one of the proposed benefits of treadmill training is that it facilitates practice of a more normal walking pattern [4,5].

The effects of body weight-supported treadmill gait training are to aid the alignment of the feet with the trunk sup-

Received: 21 August, 2014 Revised: 2 October, 2014 Accepted: 12 October, 2014

Corresponding author: Suk-Min Lee

Department of Physical Therapy, College of Health and Welfare, Sahmyook University, 815 Hwarang-ro, Nowon-gu, Seoul 139-742, Republic of Korea Tel: 82-2-3399-1632 Fax: 82-2-3399-1639 E-mail: leesm@syu.ac.kr

(c) This is an Open-Access article distributed under the terms of the Creative Commons Attribution Non-Commercial License (http://creativecommons.org/licens es/by-nc/3.0) which permits unrestricted non-commercial use, distribution, and reproduction in any medium, provided the original work is properly cited.

Copyright @ 2014 Korean Academy of Physical Therapy Rehabilitation Science 
ported by a belt on a moving treadmill, and to recover gait ability when stimulation is given in order to restore the tension of the trunk, hip, and knee extensor [9]. Body weightsupported treadmill training in stroke patients extends the duration of weight support of the paretic lower limb more than gait training on the ground, improves symmetric posture, reduces plantar flexion spasticity, and triggers a constant activity pattern of the peroneus muscle, with effects on balance and gait ability $[5,10]$.

Changes in body composition rates [11], improvement in the cardiovascular system [12], and better muscle strength and endurance [13] have been reported as effects of forward gait exercise. In general, forward gait is widely performed as a training method; however, some recent research has been conducted on backward gait with stroke patients as subjects [14]. Thorstensson [15] noted that during forward and backward gait, the potentials at the hip joints, knee joints, and ankle joints were similar. However, during backward gait in particular, reverse action between the flexors and the extensor occurred in the ankle joints and activity of the foot flexors appeared during backward gait support. Backward gait has been reported to increase stroke patients' motor control ability, lower limb muscle strength, balance ability, and gait ability $[16,17]$.

Studies have been conducted recently with stroke patients [18], spinal cord injury patients [19], and cerebral palsy patients [20] as the subjects of body weight-supported treadmill training. Research comparing the results with training on the ground [1], research comparing weight-support rates [4,21], research using speed changes [22,23], all reported that body weight-supported treadmill training was effective.

In particular, in attempting to improve the gait of stroke patients using the existing weight-supported treadmill gait training, it is difficult to change the gait pattern of stroke patients by maintaining a constant forward gait and speed, which are training parameters. Simultaneous application of weight-supported treadmill training and backward and forward gait training to improve gait ability is an important variable in the effort to enhance the gait pattern or ability of patients with an upper motor neuron lesion.

Accordingly, this study aimed to examine the effects of progressive body weight-supported forward and backward gait training on changes in stroke patients' gait ability and to examine differences between progressive body weight-supported forward and backward gait training, thereby presenting diverse therapeutic protocols for stroke patients' gait and functional improvement.

\section{Methods}

\section{Subjects and procedure}

The subjects of this study were 36 stroke patients hospitalized in the rehabilitation center of a general hospital in Korea. The selection criteria were: patients who medically had had stroke for at least six months; age $<70$ years; had no joint contracture, pain, or fractures in their musculoskeletal system, or hemianopia based on their medical records; and passive dorsiflexion of the affected ankle to a neutral position. All subjects understood the content of the study and voluntarily participated in the study. This study was a randomized controlled trial. Rondomization was done by computer-generated random numbers in which a list of random numbers was generated. The numbers were assigned according to the order of the subjects' admission to the hospital. The subject were then assigned to 1 of 3 groups: participants were assigned to progressive body weight-supported forward and backward gait training (number 1), progressive body weight-supported forward gait training (number 2), or progressive body weight-supported backward gait training (number 3 ). The subjects received gait training for three weeks, after which they were followed up for three weeks. This study was approved by the institutional human research review board of Sahmyook University.

\section{Intervention}

The study was conducted for a total of six weeks from June to August 2013. Progressive body weight support treadmill walking training was implemented for three weeks and the subjects were evaluated after the three weeks of training. As a follow-up test, the subjects were evaluated six weeks after the beginning of the training to examine the persistency of the exercise effects. The subjects were divided into a progressive body weight support treadmill forward \& backward walking training (FBWT) group of 12 subjects, a progressive body weight support treadmill forward walking training (FWT) group of 12 subjects, and a progressive body weight support treadmill backward walking training (BWT) group of 12 subjects, and they underwent the training for 30 minutes at a time.

The BWT group performed forward and backward walking wearing a suspension system on a treadmill while the degree of body weight support was progressively decreasing. In the experiment, body weight support was progressively reduced weekly, from $40 \%$ of the body weight for the first week after the beginning of the training program to $30 \%$ for 


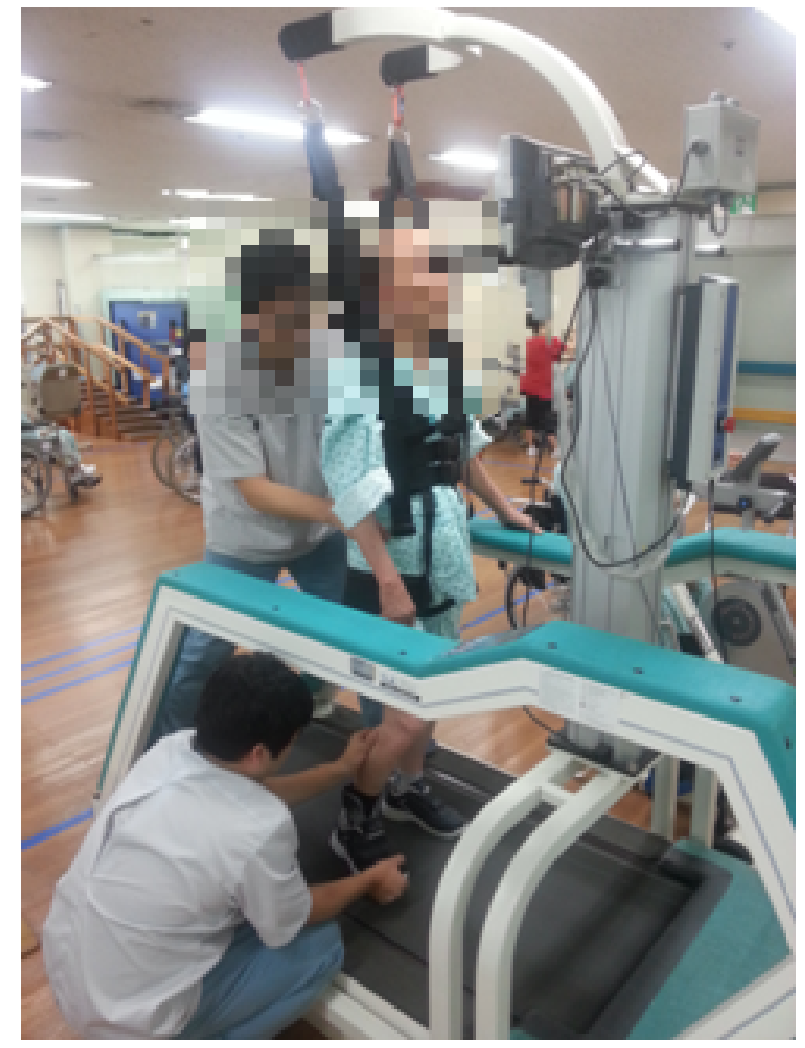

Figure 1. Progressive body weight support treadmill forward walking training.

the second week and $20 \%$ for the third week $[5,24,25]$. The participants' average forward walking speeds were 0.6-1.0 $\mathrm{km} / \mathrm{h}$ and average backward walking speeds were 0.4-0.9 $\mathrm{km} / \mathrm{h}$. The patients selected the beginning treadmill walking speeds that they considered appropriate while walking on the ground, and when each patient could stably walk for 20 seconds or longer [26], the treadmill walking speed was increased by $0.1 \mathrm{~km} / \mathrm{h}$ each time [19]. Two physical therapists participated in the training to help the subjects with the walking training. One physical therapist took his position right behind the subject to help the subject with proper body weight support, and the other physical therapist took his position at the side of the subject's affected leg to assist the subject's steps and control the lower extremity movements during swing phases and stance phases, and there after using his hands to correct the subject's forward walking patterns for 15 minutes and backward walking patterns for 15 minutes (Figures 1,2). When a patient showed fatigue, signs of pain, abnormalities of breathing, or changes in complexion after beginning the walking training, a rest for five minutes was allowed [27].

The FWT group and the BWT group performed forward

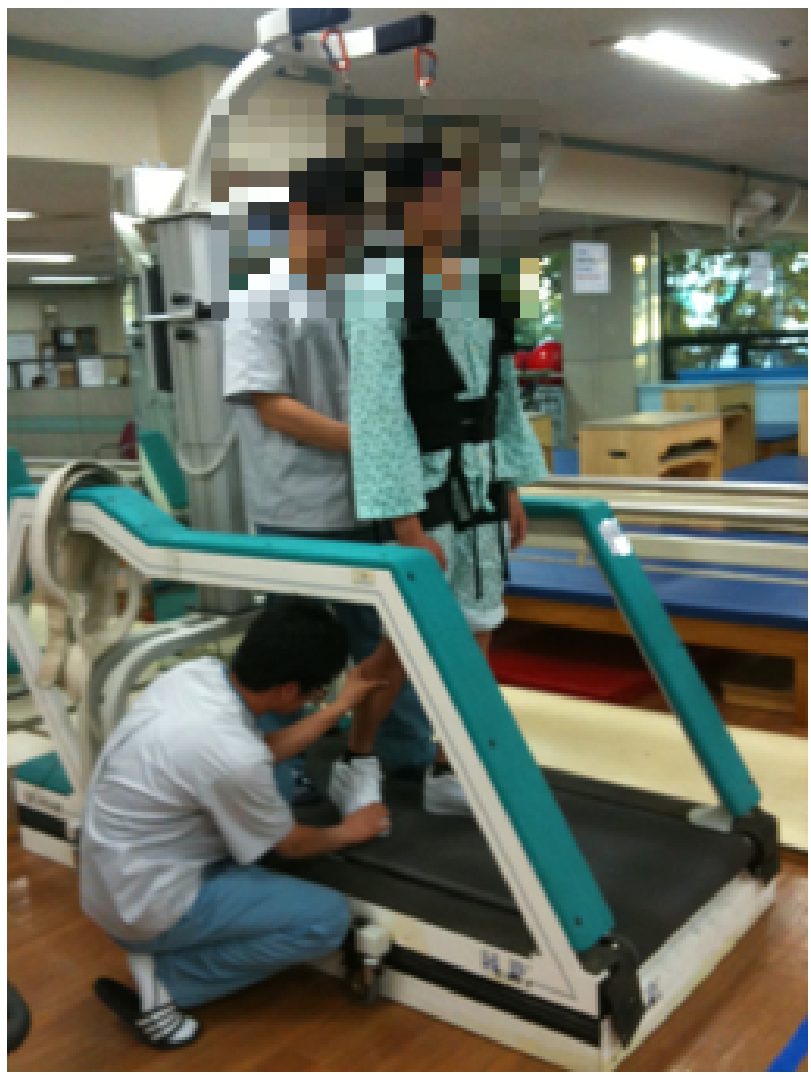

Figure 2. Progressive body weight support treadmill backward walking training.

walking training for 30 minutes and backward walking training for 30 minutes, respectively, and the other parts of their training were implemented in the same way as in the FBWT group.

\section{Outcome measures}

In order to collect data on quantitative gait analysis on the subjects' gait types, a gait analyzer (OptoGait; Microgate Srl, Bolzano, Italy, 2010) was used. The following characteristics of walking were analyzed: step length, total double support, stride time, cadence, and gait speed. In order to remove variations among the examiners, a proficient physical therapist made all measurements without a gait aid such as a weight supporter and suspension device.

For the $10-\mathrm{m}$ walk test (10MWT), the subjects were instructed to walk a total of $14 \mathrm{~m}$ at their fastest speed, and speed for the ten meters excluding the first two meters and the last two meters was measured [28]. The unit of gait speed was expressed to the second. To ensure that the subjects adapted to the training, they walked three times and the average speed was derived. Intrarater reliability was $r=0.89-1.00$ 
Table 1. The general characteristics of the subjects $(\mathrm{N}=36)$

\begin{tabular}{|c|c|c|c|c|c|}
\hline Variable & FBWT group $(\mathrm{n}=12)$ & FWT group $(n=12)$ & BWT group $(n=12)$ & $\mathrm{F} / x^{2}$ & $p$ \\
\hline Height $(\mathrm{cm})$ & $166.18(4.66)$ & $164.21(6.44)$ & $163.71(3.88)$ & $0.331^{\mathrm{b}}$ & 0.446 \\
\hline Weight (kg) & $67.65(9.18)$ & $65.28(10.83)$ & $66.83(5.89)$ & $0.055^{\mathrm{b}}$ & 0.804 \\
\hline Age (y) & $51.00(14.60)$ & $52.75(9.21)$ & $50.25(16.69)$ & $0.058^{\mathrm{b}}$ & 0.884 \\
\hline MMSE-K (score) & $27.22(1.64)$ & $27.92(1.08)$ & $27.17(1.59)$ & $0.118^{\mathrm{b}}$ & 0.136 \\
\hline Onset (mo) & $11.33(3.76)$ & $11.00(4.22)$ & $11.83(3.46)$ & $0.801^{\mathrm{b}}$ & 0.856 \\
\hline \multicolumn{6}{|l|}{ Gender } \\
\hline Male & $8(66.7)$ & $8(66.7)$ & $9(75.0)$ & $0.877^{\mathrm{a}}$ & 0.262 \\
\hline Female & $4(33.3)$ & $4(33.3)$ & $3(25.0)$ & & \\
\hline \multicolumn{6}{|l|}{ Diagnosis } \\
\hline Infarction & $4(33.3)$ & $8(66.7)$ & $5(41.7)$ & $0.235^{\mathrm{a}}$ & 2.898 \\
\hline Hemorrhage & $8(66.7)$ & $4(33.3)$ & $7(58.3)$ & & \\
\hline \multicolumn{6}{|l|}{ Affected side } \\
\hline Left & $6(50.0)$ & $6(50.0)$ & $4(33.3)$ & $0.638^{\mathrm{a}}$ & 0.900 \\
\hline Right & $6(50.0)$ & $6(50.0)$ & $8(66.7)$ & & \\
\hline
\end{tabular}

Values are presented $\mathrm{n}(\%)$ or mean $(\mathrm{SD})$.

FBWT: progressive body weight support treadmill forward \& backward walking training, FWT: progressive body weight support treadmill forward walking training, BWT: progressive body weight support treadmill backward walking training.

${ }^{\mathrm{a}}$ Chi-square test, ${ }^{\mathrm{b}} \mathrm{ANOVA}$ test.

[28].

The purpose of the 6 minutes walk test (6MWT), which was conducted in a corridor of the hospital, was to examine the subjects' gait endurance. A tape was attached to the floor along a 50-meter course, and the distance covered back and forth in six minutes was measured. When necessary, the subjects took a rest in a chair. Intrarater reliability was $r=0.91$ [29]. The test was performed three times, with the subjects resting for at least two minutes between tests, and an average value was derived.

\section{Data and statistical analysis}

All statistical analyses in this study were conducted using PASW Statistics ver. 18.0 for Windows (IBM Co., Armonk, NY, USA). Among the general characteristics of the three groups, gender, diagnoses, paretic side, and whether walking aids were used were tested using chi-squared tests. The homogeneity of the dependent variables, such as height, weight, age, and Korean Mini-Mental State Examination scores, among the three groups were tested through one-way analyses of variance (ANOVA) before the training. Repeated measure ANOVA were conducted to compare the differences between 0-3 weeks of the training and 3-6 weeks of the training within each of the groups, and to compare the differences between two of the three groups before the training, three weeks after the beginning of training, and six weeks after the beginning of training. To observe the differences between groups, the Bonferroni post-hoc test was used. The statistical significance level of all data was set to $\alpha=0.05$.

\section{Results}

The general characteristics of the study subjects are shown in Table 1. According to the results of this study, there were significant changes in gait characteristics within each group $(p<0.05)$. There were significant differences among the three groups in stride length, double limb support stance, cadence, $10 \mathrm{~m} \mathrm{WT}$, and 6 minutes WT in the third week, and only in stride length , $10 \mathrm{~m} \mathrm{WT}$, and 6 minutes WT in the sixth week $(p<0.05)$ (Table 2$)$. Changes of stride length, total double support, cadence, gait speed, $10 \mathrm{~m} \mathrm{WT}$, and $6 \mathrm{~min}$ WT among the three groups are shown in Figure 3.

\section{Discussion}

This study aimed to examine the effects of progressive body weight-supported gait training on stroke patients' gait ability, to verify the method of effectively applying body weight-supported treadmill gait training according to the degree of weight support and the methods of gait training, and to apply the training in the clinical field. According to the results of this study, there were significant differences within each group in performance before the training, three weeks after the training, and six weeks after the training. In addition, there was improvement in most items in the progressive 
Table 2. Comparison of walking ability among the three groups

$(\mathrm{N}=36)$

\begin{tabular}{|c|c|c|c|c|c|}
\hline \multirow{2}{*}{ Variable } & FBWT group & FWT group & BWT group & \multirow{2}{*}{$\mathrm{F}$} & \multirow{2}{*}{$p$} \\
\hline & Mean (SD) & Mean (SD) & Mean (SD) & & \\
\hline \multicolumn{6}{|l|}{ Stride length $(\mathrm{cm})$} \\
\hline 0 week & $83.33(11.65)$ & $82.58(18.36)$ & $83.08(16.41)$ & & \\
\hline 3 weeks & $97.19(10.12)^{\mathrm{a}}$ & $88.77(17.41)^{\mathrm{a}, *}$ & $89.66(19.44)^{\mathrm{a}, *}$ & 8.025 & 0.001 \\
\hline 6 weeks & $99.74(10.43)^{b}$ & $93.15(15.89)^{\mathrm{b}}$ & $97.68(20.50)^{\mathrm{b},{ }^{*}}$ & 5.801 & 0.012 \\
\hline$p$ & 0.048 & 0.005 & 0.037 & & \\
\hline \multicolumn{6}{|c|}{ Total double support (\%) } \\
\hline 0 week & $34.00(10.10)$ & $32.57(8.30)$ & $34.16(7.14)$ & & \\
\hline 3 weeks & $28.15(7.80)^{\mathrm{a}}$ & $27.16(6.12)^{\mathrm{a}}$ & $29.75(7.65)^{\mathrm{a}}$ & 0.141 & 0.869 \\
\hline 6 weeks & $27.83(6.53)$ & $26.40(5.73)$ & $28.88(7.01)$ & 0.155 & 0.857 \\
\hline$p$ & 0.041 & 0.003 & 0.001 & & \\
\hline \multicolumn{6}{|l|}{ Cadence (step/sec) } \\
\hline 0 week & $0.51(0.17)$ & $0.51(0.15)$ & $0.50(0.11)$ & & \\
\hline 3 weeks & $0.78(0.16)^{\mathrm{a}}$ & $0.66(0.12)^{\mathrm{a}}$ & $0.62(0.09)^{\mathrm{a},{ }^{*}}$ & 3.435 & 0.044 \\
\hline 6 weeks & $0.77(0.16)$ & $0.70(0.14)^{\mathrm{b}}$ & $0.70(0.14)^{b}$ & 2.420 & 0.105 \\
\hline$p$ & 0.000 & 0.004 & 0.000 & & \\
\hline \multicolumn{6}{|l|}{ Gait speed $(\mathrm{m} / \mathrm{s})$} \\
\hline 0 week & $0.62(0.25)$ & $0.72(0.25)$ & $0.75(0.31)$ & & \\
\hline 3 weeks & $0.88(0.35)^{\mathrm{a}}$ & $0.85(0.33)^{\mathrm{a}}$ & $0.88(0.37)^{\mathrm{a}}$ & 2.312 & 0.115 \\
\hline 6 weeks & $0.91(0.43)$ & $0.91(0.38)$ & $0.92(0.30)$ & 0.078 & 0.925 \\
\hline$p$ & 0.000 & 0.016 & 0.015 & & \\
\hline \multicolumn{6}{|c|}{$10 \mathrm{~m}$ walk test $(\mathrm{m} / \mathrm{s})$} \\
\hline 0 week & $0.61(0.22)$ & $0.62(0.22)$ & $0.60(0.23)$ & & \\
\hline 3 weeks & $0.89(0.21)^{\mathrm{a}}$ & $0.80(0.28)^{\mathrm{a},{ }^{*}}$ & $0.80(0.25)^{\mathrm{a},{ }^{*}}$ & 5.577 & 0.008 \\
\hline 6 weeks & $0.91(0.22)^{\mathrm{b}}$ & $0.85(0.28)^{\mathrm{b}}$ & $0.86(0.25)^{\mathrm{b}, *}$ & 4.705 & 0.016 \\
\hline$p$ & 0.000 & 0.000 & 0.000 & & \\
\hline \multicolumn{6}{|c|}{6 minutes walk test $(\mathrm{m})$} \\
\hline 0 week & $239.83(46.43)$ & $236.83(50.07)$ & $239.25(47.69)$ & & \\
\hline 3 weeks & $279.83(39.22)^{\mathrm{a}}$ & $259.83(45.10)^{\mathrm{a},{ }^{*}}$ & $266.00(46.93)^{\mathrm{a},{ }^{*}}$ & 6.644 & 0.004 \\
\hline 6 weeks & $288.25(35.49)^{\mathrm{b}}$ & $276.67(41.33)^{\mathrm{b}}$ & $274.08(48.17)^{\mathrm{b}, *}$ & 5.035 & 0.012 \\
\hline$p$ & 0.000 & 0.000 & 0.000 & & \\
\hline
\end{tabular}

FBWT: progressive body weight support treadmill forward \& backward walking training, FWT: progressive body weight support treadmill forward walking training, BWT: progressive body weight support treadmill backward walking training.

${ }^{a}$ Significantly different compared with 0-3 weeks, ${ }^{\text {b }}$ significantly different compared with 3-6 weeks.

significantly different compared with FBWT.

body weight-supported forward and backward gait training group compared with the other groups.

In this study, stride length was derived using OptoGait in order to examine gait variables. The result was that there was an increase in all three groups. Comparisons among the three groups indicated significant improvement in the forward and backward gait training group compared to the other two groups in the third week. Significant improvement was also seen in the backward gait training and forward and backward gait training groups compared with the forward gait training group in the sixth week. In a study by Ada et al. [7], stroke patients residing in a local community received treadmill or ground gait training for four weeks, and the step length of their paretic side increased from $0.42 \mathrm{~m}$ before the experiment to $0.51 \mathrm{~m}$ after the experiment. In a three-month follow up test, the step length was $0.51 \mathrm{~m}$ with sustained exercise effect, which was consistent with the result of the present study. Yang et al. [14] studied 25 stroke patients who were able to walk independently, applying a general treatment to both the experimental group and the control group for 40 minutes. In addition, they had the experimental group receive backward gait training three time per week, $30 \mathrm{mi}-$ nutes each time, for three weeks; the experimental group's stride improved from $0.78 \mathrm{~m}$ before the intervention to $0.88 \mathrm{~m}$ after the intervention, which was consistent with the present study's results. By gradually reducing the rate of weight support in the body weight-supported treadmill gait training, the patients gained self-confidence, and the activity of their extensors engaging in postural support increased, resulting in better functional movement of the paretic side. In addition, 

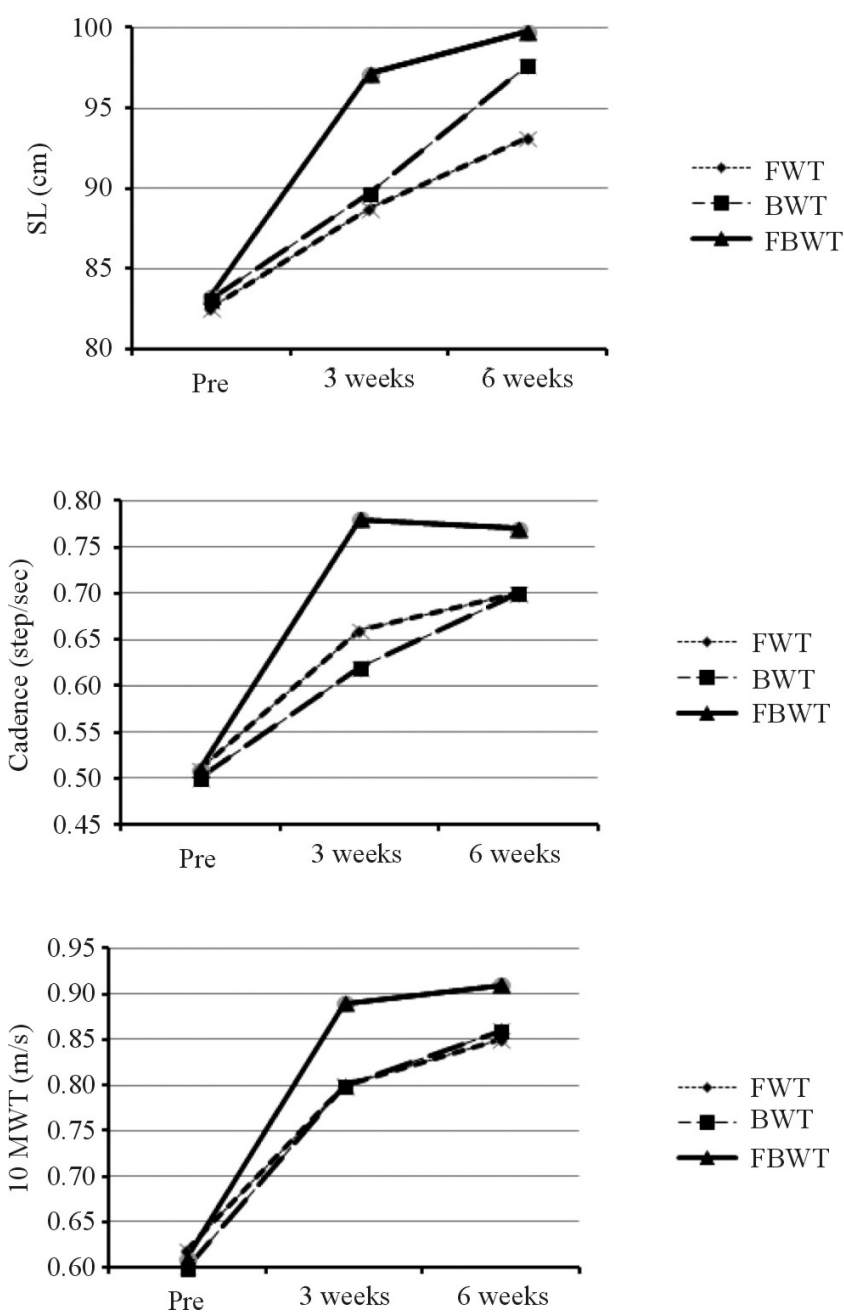
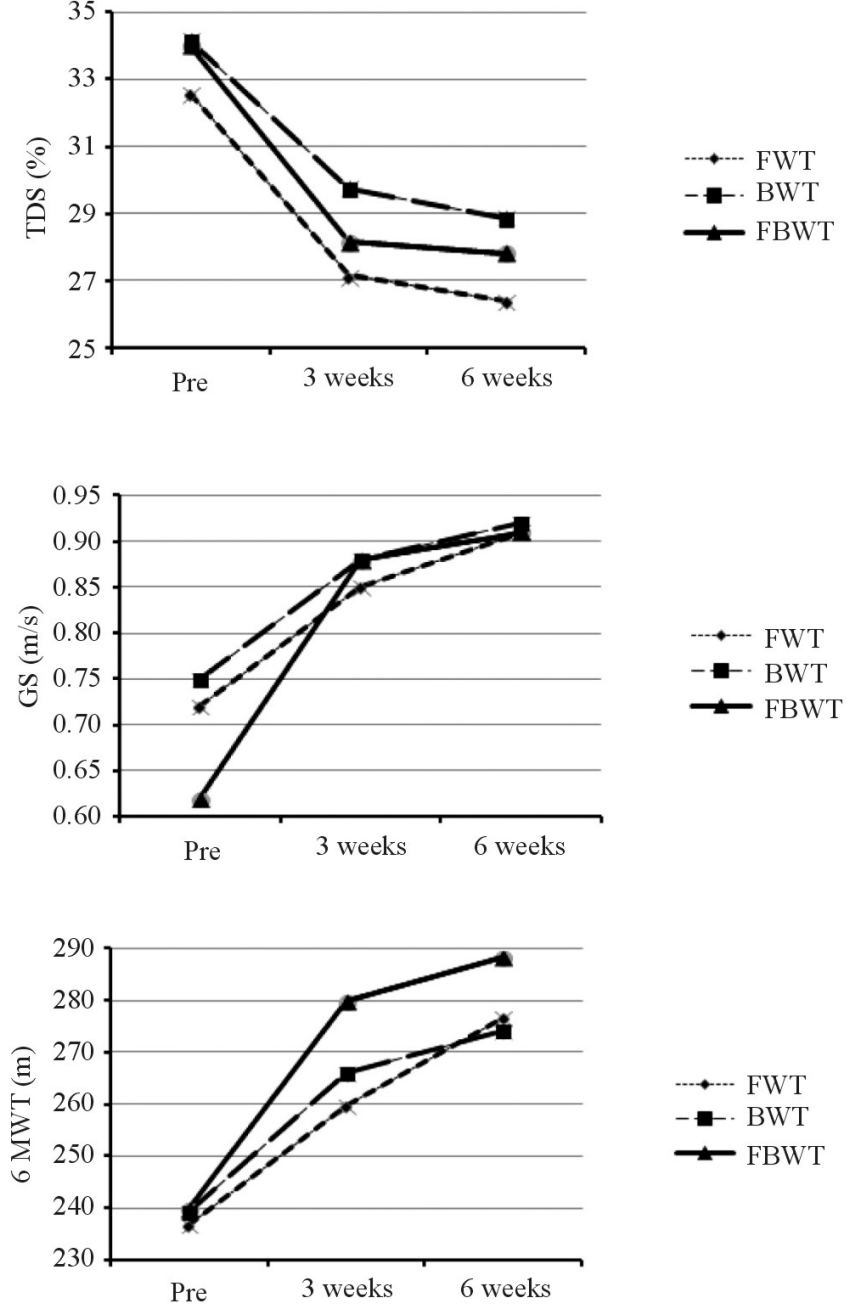

Figure 3. Change of stride length (SL), total double support (TDS), cadence, gait speed (GS), 10-m walk test, and 6 minute walk test among the three groups. FBWT: progressive body weight support treadmill forward \& backward walking training, FWT: progressive body weight support treadmill forward walking training, BWT: progressive body weight support treadmill backward walking training.

the repetitive treadmill gait and task-oriented approach increased automatic movement during gait training, thereby improving stride length.

This study calculated total double support in order to examine gait variables. There was a statistically significant increase in the three groups from the initiation of the intervention to the third week, but not from the third week to the sixth week. Harris-Love et al. [30] compared stroke patients' stance phase, single limb support stance, and rate of stance phase and swing phase while they walked on the ground and on a treadmill. They observed that the stance phase of the paretic lower limb and single limb support stance during treadmill gait increased significantly, and that as the difference between the lower limbs of the paretic side and non-paretic side decreased, training with symmetric gait pattern was enabled, which is consistent with the present study's results. In a study by Chen et al. [24] in which eight stroke patients received treadmill gait training at different gait speeds $(70 \%, 100 \%$, and $130 \%)$, with and without weight support, with and without a handrail attached, and according to degree of spasticity, the combination of weight support and use of a handrail increased single limb support rate, which is consistent with the present study's results. Increased feedback though the sensory receptors of the soles led to weight movement and support onto the non-paretic and paretic sides in a proper and precise direction, as well as improvement in the lower limbs' muscle strength and motor learning ability and reduction in double limb support stance.

This study calculated cadence in order to examine gait variables. The cadence of the forward gait training group 
and the backward gait training group increased, while that of the forward and backward gait training group increased until the third week, but then decreased from the third week to the sixth week. In the third week, there were significant changes in the forward and backward gait training group and the backward gait training group compared with the forward gait training group; however, there were no significant differences among the three groups in the sixth week. Bayat et al. [31] compared the effects ground gait and treadmill gait on stroke patients' gait, and noted that when they walked at the same speed, the subjects used a different gait strategy, due to the increased cadence and faster speed on the treadmill. In the present study, an increase in cadence means that the subjects came to have an ability to walk for a longer distance at a more stable and faster speed and with a longer stride after three weeks of training than before the training. In addition, under the body weight-supported treadmill gait training, continuous input of afferent information into the proprioceptive senses led to increased reflexive gait pattern, sustained maintenance of the stance phase of the paretic lower limb, longer and consistent stride, decreased spasticity of the ankle plantar flexors, and activated muscles around the ankles.

This study calculated gait speed in order to examine gait variables. There was a statistically significant increase in the three groups from the initiation of the intervention to the third week, but not from the third week to the sixth week. And this study calculated 10MWT in order to examine gait variables. The result was that there was an increase in all three groups. Comparisons among the three groups indicated significant improvement in the forward and backward gait training group compared to the other two groups in the third week. Significant improvement was also seen in the backward gait training and forward and backward gait training groups compared with the forward gait training group in the sixth week. In a study by Ada et al. [7] in which stroke patients residing in a local community conducted gait training using a treadmill for four weeks, their gait speed improved by $0.12 \mathrm{~m} / \mathrm{s}$. In a study by Barbeau and Visintin [8] on optimal body weight-supported treadmill gait training with 100 stroke patients as the subjects, the experimental group was put on a suspension unit with $40 \%$ weight support and the control group wore a suspension unit with no weight support. The result was that both groups' gait speed on a treadmill increased more than their gait speed on the ground did. In addition, the experimental group had a greater increase in gait speed, which is consistent with the present study's results. In a study by Yang et al. [14] with 25 stroke patients who were able to walk $11 \mathrm{~m}$ independently, both the experimental and control groups received general treatment for 40 minutes, and the experimental group conducted gait training three times per week, 30 minutes each time, for three weeks. The gait speed of the experimental group improved from $24.83 \mathrm{~m} / \mathrm{min}$ to $33.43 \mathrm{~m} / \mathrm{min}$, which is consistent with the present study's results. During progressive body weight-supported gait training, lower limb movements are activated, contraction of the quadriceps femoris muscle results in stability of the knee joints, muscles necessary for gait are evenly promoted, and ankle movements are increased, triggering gait propulsion in the ankles, which is considered sufficient as clinical and functional effects. Stability of the joints and muscles necessary for gait were evenly promoted in this study, and therefore, functional movements of the lower limbs increased, improving gait speed.

This study calculated 6MWT in order to examine gait variables. The result was that there was an increase in all three groups. Comparisons among the three groups indicated significant improvement in the forward and backward gait training group compared to the other two groups in the third week. Significant improvement was also seen in the backward gait training and forward and backward gait training groups compared with the forward gait training group in the sixth week. In a study by Ada et al. [7] on the effects of treadmill gait training and ground gait training programs on stroke patients' gait ability, the experimental group conducted treadmill gait training and ground gait training and the control group performed lower limb stretching and muscle strengthening training. In that study, the experimental group saw improvement in gait speed and endurance, which is consistent with the present study's results. The longer stride and increased gait speed led to improved muscle strength and cardiopulmonary functions, making it possible to walk a longer distance and increasing gait endurance.

The progressive body weight-supported treadmill gait training used in the present study will become one of methods to select for treatment, with a main focus on gait improvement according to each patient's condition. It is considered that research on different types of body weight-supported treadmill is necessary to increase the potential capabilities of patients with an upper motor neuron lesion.

This study verified that progressive body weight-supported treadmill gait training positively affected the gait ability of stroke patients in an actual gait environment. It al- 
so showed that progressive body weight-supported forward and backward gait training was more effective than progressive body weight-supported forward gait training and progressive body weight-supported backward gait training. Therefore, progressive weight-supported forward and backward gait training should be used as a gait training program for stroke patients receiving rehabilitation treatment who can walk independently, and therefore, will return to their local community.

\section{Conflict of Interest}

The authors declared no potential conflicts of interest with respect to the authorship and/or publication of this article.

\section{References}

1. Eich HJ, Mach H, Werner C, Hesse S. Aerobic treadmill plus Bobath walking training improves walking in subacute stroke: a randomized controlled trial. Clin Rehabil 2004;18:640-51.

2. Thrift A, McNeil J, Donnan G; Melbourne Risk Factor Study Group. Reduced frequency of high cholesterol levels among patients with intracerebral haemorrhage. J Clin Neurosci 2002; 9:376-80.

3. Werner C, Von Frankenberg S, Treig T, Konrad M, Hesse S. Treadmill training with partial body weight support and an electromechanical gait trainer for restoration of gait in subacute stroke patients: a randomized crossover study. Stroke 2002; 33:2895-901.

4. Hassid E, Rose D, Commisarow J, Guttry M, Dobkin B. Improved gait symmetry in hemiparetic stroke patients induced during body weight-supported treadmill stepping. J Neuro Rehabil 1997;11:21-6.

5. Hesse S, Konrad M, Uhlenbrock D. Treadmill walking with partial body weight support versus floor walking in hemiparetic subjects. Arch Phys Med Rehabil 1999;80:421-7.

6. Miller EW, Quinn ME, Seddon PG. Body weight support treadmill and overground ambulation training for two patients with chronic disability secondary to stroke. Phys Ther 2002;82: 53-61.

7. Ada L, Dean CM, Hall JM, Bampton J, Crompton S. A treadmill and overground walking program improves walking in persons residing in the community after stroke: a placebo-controlled, randomized trial. Arch Phys Med Rehabil 2003;84:1486-91.

8. Barbeau H, Visintin M. Optimal outcomes obtained with body-weight support combined with treadmill training in stroke subjects. Arch Phys Med Rehabil 2003;84:1458-65.

9. Finch L, Barbeau H, Arsenault B. Influence of body weight support on normal human gait: development of a gait retraining strategy. Phys Ther 1991;71:842-55.

10. Hesse S, Werner C, Bardeleben A, Barbeau H. Body weight-supported treadmill training after stroke. Curr Atheroscler Rep 2001;3:287-94.
11. Ohta T, Kawamura T, Hatano K, Yokoi M, Uozumi Z, Okamoto $\mathrm{N}$, et al. Effects of exercise on coronary risk factors in obese, middle-aged subjects. Jpn Circ J 1990;54:1459-64.

12. Duncan JJ, Gordon NF, Scott CB. Women walking for health and fitness. How much is enough? JAMA 1991;266:3295-9.

13. Flynn TW, Connery SM, Smutok MA, Zeballos RJ, Weisman IM. Comparison of cardiopulmonary responses to forward and backward walking and running. Med Sci Sports Exerc 1994; 26:89-94.

14. Yang YR, Yen JG, Wang RY, Yen LL, Lieu FK. Gait outcomes after additional backward walking training in patients with stroke: a randomized controlled trial. Clin Rehabil 2005;19:264-73.

15. Thorstensson A. How is the normal locomotor program modified to produce backward walking? Exp Brain Res 1986;61:664-8.

16. Threlkeld AJ, Horn TS, Wojtowicz G, Rooney JG, Shapiro R. Kinematics, ground reaction force, and muscle balance produced by backward running. J Orthop Sports Phys Ther 1989;11:56-63.

17. Thomas MA, Fast A. One step forward and two steps back: the dangers of walking backwards in therapy. Am J Phys Med Rehabil 2000;79:459-61.

18. Laufer Y, Dickstein R, Chefez Y, Marcovitz E. The effect of treadmill training on the ambulation of stroke survivors in the early stages of rehabilitation: a randomized study. J Rehabil Res Dev 2001;38:69-78.

19. Ditor DS, Macdonald MJ, Kamath MV, Bugaresti J, Adams M, McCartney N, et al. The effects of body-weight supported treadmill training on cardiovascular regulation in individuals with motor-complete SCI. Spinal Cord 2005;43:664-73.

20. McNevin NH, Coraci L, Schafer J. Gait in adolescent cerebral palsy: the effect of partial unweighting. Arch Phys Med Rehabil 2000;81:525-8.

21. Visintin M, Barbeau H, Korner-Bitensky N, Mayo NE. A new approach to retrain gait in stroke patients through body weight support and treadmill stimulation. Stroke 1998;29:1122-8.

22. Pohl M, Mehrholz J, Ritschel C, Rückriem S. Speed-dependent treadmill training in ambulatory hemiparetic stroke patients: a randomized controlled trial. Stroke 2002;33:553-8.

23. Sullivan KJ, Knowlton BJ, Dobkin BH. Step training with body weight support: effect of treadmill speed and practice paradigms on poststroke locomotor recovery. Arch Phys Med Rehabil 2002;83:683-91.

24. Chen HY, Wing AM, Pratt D. The synchronisation of lower limb responses with a variable metronome: the effect of biomechanical constraints on timing. Gait Posture 2006;23:307-14.

25. Schwartz I, Sajin A, Moreh E, Fisher I, Neeb M, Forest A, et al. Robot-assisted gait training in multiple sclerosis patients: a randomized trial. Mult Scler 2012;18:881-90.

26. Yang YR, Chen YC, Lee CS, Cheng SJ, Wang RY. Dual-task-related gait changes in individuals with stroke. Gait Posture 2007;25:185-90.

27. Kesar TM, Reisman DS, Perumal R, Jancosko AM, Higginson JS, Rudolph KS, et al. Combined effects of fast treadmill walking and functional electrical stimulation on post-stroke gait. Gait Posture 2011;33:309-13.

28. Dean CM, Richards CL, Malouin F. Task-related circuit training improves performance of locomotor tasks in chronic stroke: a randomized, controlled pilot trial. Arch Phys Med Rehabil 2000;81:409-17. 
29. Mossberg KA. Reliability of a timed walk test in persons with acquired brain injury. Am J Phys Med Rehabil 2003;82:385-90.

30. Harris-Love ML, Forrester LW, Macko RF, Silver KH, Smith GV. Hemiparetic gait parameters in overground versus treadmill walking. Neurorehabil Neural Repair 2001;15:105-12.

31. Bayat R, Barbeau H, Lamontagne A. Speed and temporal-distance adaptations during treadmill and overground walking following stroke. Neurorehabil Neural Repair 2005;19:115-24. 